INDO GLOBAL JOURNAL OF

PHARMACEUTICAL SCIENCES

ISSN 2249- 1023

\title{
The Exhaustive Study for the Antioxidant \& Antibacterial Potential of Clove (Syzygium Aromaticum) and Cinnamon (Cinnamomum Verum)
}

\author{
Deepshikha Gupta *, Girija \\ Amity Institute of Applied Sciences, Amity University, Sector-125, Noida-201301, India
}

Address for Correspondence: Deepshikha Gupta; dgupta2@amity.edu

\begin{abstract}
Methanolic extracts of dried and powdered samples of Clove (Syzygium aromaticum) and Cinnamon (Cinnamomum verum) were analyzed for their total phenolic content (TPC), Total Antioxidant Capacity (TAC) using DPPH assay, ABTS assay and FRAP assay. The extracts were also analysed for their antibacterial activity against a gram positive bacteria (Staphylococcous aureus) and a gram negative bacteria (Escherichia coli). Finally GCMS studies of the methanolic extracts were done in order to identify the major active constituents present in them responsible for its antioxidant and antibacterial activity. Clove showed higher values of TPC which was calculated in terms of Gallic acid Equivalent (GAE). DPPH assay and ABTS assay both involved radical scavenging capacity and were calculated as \% reduction. DPPH assay showed $86 \%$ reduction in activity after $1 \mathrm{hr}$ and $94 \%$ reduction after $24 \mathrm{hrs}$ for clove extract while cinnamon extract showed $73 \%$ reduction after $1 \mathrm{hr}$ and $88 \%$ reduction after $24 \mathrm{hrs}$ of analysis. ABTS assay showed $88.6 \%$ reduction after $1 \mathrm{hr}$ and $93 \%$ after 3 hrs of analysis for clove extract while cinnamon extract showed $81.8 \%$ after $1 \mathrm{hr}$ and $88.9 \%$ after 3 hrs. FRAP values were calculated in terms of $\mathrm{mM}$ concentration of $\mathrm{FeSO}_{4}$. Clove showed FRAP values equivalent to $4.746 \mathrm{mM}$ of $\mathrm{FeSO}_{4}$ while cinnamon showed $4.679 \mathrm{mM}$ of $\mathrm{FeSO}_{4}$. Antibacterial studies showed ZOI of $15 \mathrm{~mm}$ each against both the bacterial species at concentration of $0.5 \mathrm{mg} / \mathrm{ml}$ which was compared with a positive control i.e., Chloramphenicol. GCMS studies showed high \% of eugenol, isoeugenol, Caryophyllene and eugenyl acetate in clove extract. Cinnamon extract showed the presence of cinnamaldehyde, p-methoxy cinnamaldehyde, coumarin and cadinol. () 2014 iGlobal Research and Publishing Foundation. All rights reserved.
\end{abstract}

Conference Proceedings: International Conference on Life Sciences, Informatics, Food and Environment; August 29- 30, 2014

Indo Global Journal of Pharmaceutical Sciences( ISSN 22491023 ; CODEN- IGJPAI; NLM ID: 101610675) indexed and abstracted in EMBASE(Elsevier), SCIRUS(Elsevier),CABI, CAB Abstracts, Chemical Abstract Services(CAS), American Chemical Society(ACS), Index Copernicus, EBSCO, DOAJ, Google Scholar and many more. For further details, visit 